\title{
La creación audiovisual en la infancia. Estudio de experiencias en contextos educativos
}

\author{
The audiovisual creation in childhood. Study of experiences in \\ educational contexts
}

Gabriela Paula AUGUSTOWSKY. Universidad Nacional de las Artes (Argentina). gabrielaug@yahoo.com

Resumen: Este trabajo aborda la creación audiovisual en la infancia como práctica educativa en el contexto contemporáneo de expansión de propuestas.

Presenta el desarrollo y los resultados de una investigación que estudia sistemáticamente programas y proyectos de enseñanza audiovisual en España y Argentina; se analizan sus encuadres institucionales, propósitos, contenidos, estrategias didácticas, educadores y las creaciones de los niños y niñas. La didáctica audiovisual se postula como un campo de conocimiento en pleno proceso de construcción en el que se conjugan saberes y habilidades provenientes de diferentes disciplinas y con dispar estatus epistemológico. Por último, se enuncian algunos apuntes didácticos entendidos como faros para el desarrollo de nuevas experiencias e investigaciones.

Palabras clave: creación audiovisual infantil, proyectos y programas educativos, educación audiovisual, educación artística, investigación audiovisual.

Abstract: This work approaches audiovisual creation in childhood as an educational practice in the contemporary context of widening of proposals.

It presents the development and results of a research that systematically studies programs and projects of audiovisual education in Spain and Argentina; their institutional frameworks, purposes, contents, didactic strategies, educators and the creations of the children are analyzed. Audiovisual didactics is postulated as 
a field of knowledge in full construction process in which knowledge and skills from different disciplines and with different epistemological status are combined. To conclude, it is enunciated some didactic notes understood as lighthouses for the development of new experiences and investigations.

Keywords: children's audiovisual creation, educational projects and programs, audiovisual education, artistic education, audiovisual research.

\section{La creación audiovisual infantil: una práctica educativa en expansión}

El cine y otras producciones audiovisuales destinadas al público infantil y juvenil cuentan con una amplia trayectoria y décadas de afianzamiento tanto en el ámbito cultural y artístico como en el comercial. Qué miran los niños, cómo, dónde, por qué y para qué lo hacen son cuestiones atravesadas por dimensiones sociales, culturales, económicas, políticas y por tanto también temáticas de interés para el campo de la educación contemporánea. En los últimos años, asistimos a la expansión de un fenómeno que ubica a la infancia en otra posición: los niños y niñas pasaron de ser espectadores a ser también realizadores, creadores de material audiovisual. En numerosos países, se observa el surgimiento y desarrollo de propuestas educativas, programas y acciones destinados a la infancia cuyo propósito consiste en la producción audiovisual. En estas iniciativas, se realizan diferentes tipos de audiovisuales, tales como cortometrajes de animación, documentales y piezas de ficción.

Con valiosos antecedentes en las décadas de 1980 y 1990, hoy el incremento es realmente notable. Se ofrecen talleres de creación audiovisual para escolares, municipios, universidades, espacios recreativos, ámbitos de intervención socio comunitaria.

¿Por qué surgen ahora tantos proyectos de creación audiovisual para menores? ¿Por qué los pequeños ahora, además de ver, hacen películas?

Una respuesta posible es la alta disponibilidad tecnológica. El crecimiento actual se da en un entorno social atravesado por el abaratamiento y la accesibilidad funcional de los dispositivos tecnológicos que permiten la producción audiovisual aun a edades muy tempranas. Numerosas prácticas audiovisuales se transmiten en la socialización primaria; los mayores muestran - de manera más o menos conscientecuándo se hacen videos, para qué, para quién, qué merece ser registrado y mostrado. Estas acciones cotidianas ligadas al universo audiovisual configuran una base de saberes "previos" aprovechables para la formación sistemática de la infancia en este campo.

Pero esta condición contextual-que facilita y promueve su desarrollo-es insuficiente para dar cuenta de este fenómeno y comprenderlo en términos conceptuales, artísticos 
y educativos. Junto con la posibilidad técnica, se activan propósitos formativos, estrategias de enseñanza, maneras de trabajo grupal colaborativo, formas narrativas y una amplia gama de opciones para la creación infantil. Las propuestas educativas postulan lo audiovisual como un campo fértil para el despliegue de la imaginación, la expresión individual y colectiva, la exploración lúdica, el desarrollo de la autoconciencia, el trabajo colaborativo, el acceso y la democratización de prácticas y saberes históricamente reservados a las élites.

Al intentar conocer y comprender el sentido de estas actividades, surgen algunos interrogantes:¿Qué instituciones realizan estos proyectos, qué propósitos persiguen? ¿Qué formación tienen los profesionales a cargo de estas actividades, cuáles son sus concepciones acerca del arte, de la educación y de lo audiovisual? ¿Qué se enseña y qué se aprende en estas experiencias? ¿Qué estrategias didácticas se emplean? ¿Cómo intervienen las personas adultas en los procesos de creación infantil? ¿Qué características asume el trabajo grupal? ¿Cómo son los audiovisuales realizados por niños y niñas? ¿Quiénes miran lo que hacen?

\section{Investigar la educación audiovisual}

Las propuestas educativas destinadas a la creación audiovisual infantil son en comparación con otras temáticas más "clásicas" escasamente estudiadas desde una perspectiva académica. Esto se debe, en gran medida, a que muchas de estas actividades han crecido al amparo de lógicas de trabajo no escolarizadas o formalizadas y se han configurado en el hacer práctico. Así, la reflexión teórica y la producción de cuerpos conceptuales sobre la enseñanza audiovisual se desarrollan por detrás de la versatilidad y productividad de las prácticas.

De la revisión bibliográfica, surge que este es aún un campo en construcción que implica ante todo el desafío de poner en diálogo las trayectorias y el conocimiento acerca de la creación en la infancia con el valioso corpus teórico de la producción cinematográfica y audiovisual pensado inicialmente para las realizaciones adultas.

En las últimas dos décadas, las creaciones infantiles, la educación artística/visual, el cine y lo audiovisual han sido tratados y analizados por aparatos conceptuales disímiles que se presentan de modo desarticulado; sin embargo, todos tienen en común su potencialidad para incidir en las prácticas, para producir efectos y moldear acciones. En términos generales, es posible establecer tres grandes perspectivas o enfoques en la educación audiovisual: a) El cine como arte: encuentros con la alteridad y la experiencia creadora (Bergala, 2007) b) El cine como lenguaje y la alfabetización en medios audiovisuales (Buckingham, 2008; Ferrés i Prats, 2014; Kress, 2003; Morduchowicz, 2003) y c) La creación audiovisual para la democratización de saberes, la inclusión social y la ampliación de derechos (Baigorri, 2004; Barbosa, 2011; Mampaso Martínez, 2006; Ortuño, 2013). 
En cuanto al diseño de estrategias metodológicas, la temática plantea una serie de nodos problemáticos entre los que se destacan:

- la escasa tradición de la práctica específica,

- los enormes desacuerdos terminológicos que dan cuenta de los desacuerdos en relación al objeto mismo,

- la multiplicidad de propósitos formativos,

- la complejidad de los dispositivos y de los procesos de creación/producción,

- las mediaciones técnicas y tecnológicas de las prácticas,

- la autoría grupal (no individual) del trabajo de los niños,

- la participación de adultos como condición necesaria y

- la rapidez con que se renuevan las propuestas educativas.

La investigación La creación audiovisual infantil como práctica educativa. Estudio de experiencias y discursos en contexto (Augustowsky, 2015) indaga sistemáticamente prácticas educativas en las que niños y niñas entre 4 y 12 años de edad realizan producciones audiovisuales. Las creaciones audiovisuales infantiles se abordan atendiendo a los encuadres institucionales que las promueven, sostienen y otorgan sentidos propios y específicos en cada caso.

Los objetivos del estudio son:

- Identificar y describir proyectos y programas educativos en los que niños y niñas entre 4 y 12 años realizan piezas audiovisuales.

- Caracterizar los contextos socioeducativos e institucionales en los que se desarrollan proyectos de creación audiovisual con niños y niñas.

- Indagar y establecer las concepciones de educación, las concepciones de arte y de lo audiovisual implicadas en cada uno de los proyectos/programas.

- Recuperar y analizar los discursos pedagógicos, expresivos/artísticos, sociales y políticos implicados en cada una de las propuestas; establecer sus propósitos, contenidos y estrategias didácticas.

- Analizar sistemáticamente las realizaciones de los niños y niñas; identificar preferencias temáticas, estilísticas, sentidos y significados.

- Construir categorías de análisis y diseñar herramientas metodológicas para el abordaje sistemático de la creación audiovisual infantil en el marco de diferentes condiciones y contextos educativos.

\section{Metodología}

En términos metodológicos, la indagación se inscribe en las perspectivas cualitativas interpretativas de investigación. Se realizó un estudio de casos con un diseño de enfoque progresivo. En una fase preliminar se implementó una búsqueda, 
registro y análisis sistemático de 40 proyectos. En una segunda fase se estudiaron 12 proyectos situados en España y América Latina: Cinema en Curs; Cinemalité; Telekids; Aula de cine; Taller de cine el mate; Programa de Medios en la escuela; Animate a animar; Cine + chicos; Festival Hacelo Corto; Festival Mice; Festival Nueva Mirada; Festival Ojo al Piojo! Tomando los resultados de la segunda fase y atendiendo a su localización en Argentina, se seleccionaron 3 casos para su estudio en profundidad: Animate a animar; Cine + chicos; Festival Ojo al Piojo!.

Para la recolección de información empírica durante el trabajo en terreno se emplearon los siguientes instrumentos: entrevista en profundidad, observación participante, relevamiento fotográfico sistemático (contextual y de actividades). Además se recabaron: fuentes documentales audiovisuales: cortometrajes realizados por niños/as, piezas audiovisuales realizados por los responsables del proyecto, piezas audiovisuales realizadas por canales de televisión locales, cortometrajes de animación realizados por artistas que se proyectan a los niños/as en los proyectos; fuentes documentales impresas: material didáctico para docentes, convocatorias y fichas de inscripción, catálogos y programas para niños y niñas, artículos periodísticos.

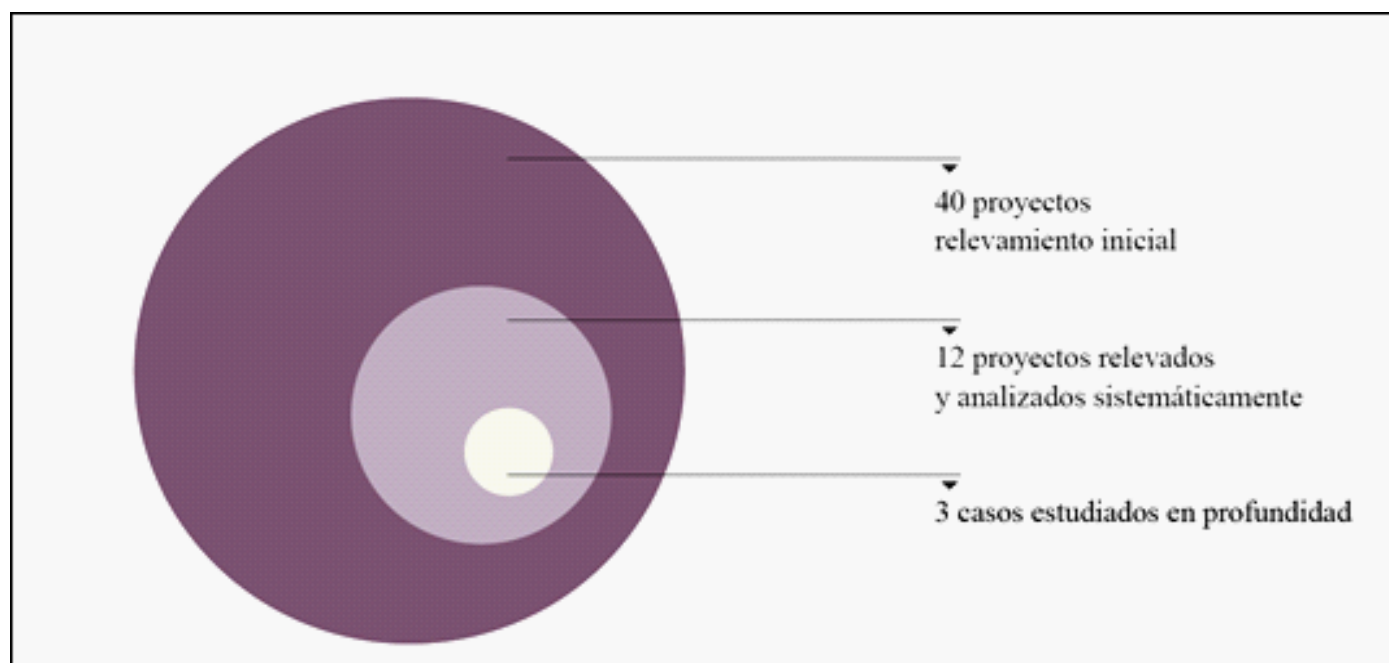

Figura 1. Estudio de casos. Diseño de enfoque progresivo. Fuente: elaboración propia.

Para el análisis de la información empírica se empleó un procedimiento cualitativo, el método comparativo constante. Este procedimiento genera en el marco del interjuego teoría empíria un sistema de categorías conceptuales para la comprensión del fenómeno en estudio. En este proceso se construyó, partiendo de los objetivos y el marco teórico, un conjunto de categorías de análisis iniciales. Estas categorías iniciales luego se completaron y enriquecieron con las categorías emergentes durante el trabajo en terreno a fin de abordar y comprender los datos en toda su multiplicidad y singularidad. Durante el estudio de casos se implementó un proceso de revisión de los interesados entendido como una instancia de retroalimentación y triangulación de las observaciones e interpretaciones realizadas (por la investigadora). 
AUGUSTOWSKY / La creación audiovisual en la infancia. Estudio de experiencias en contextos educativos

\section{Los programas y proyectos: una caracterización general}

A partir de las 12 propuestas estudiadas sistemáticamente en España y Argentina se observa que estas son parte de una trama organizacional compleja y a la vez flexible que les posibilita establecer alianzas e ir adaptándose a distintas necesidades eventuales. Los programas de creación audiovisual para niños y niñas configuran espacios de cooperación geográfica, institucional, tecnológica y profesional. Uno de los formatos institucionales que asumen los proyectos es el de asociación cultural $\mathrm{u}$ organización sin ánimo de lucro. Algunos proyectos dependen directamente de un estamento gubernamental, varios se desarrollan en el marco de universidades. En todos los casos se registran convenios entre más de una institución, los términos asociación, apoyo, auspicio se mencionan en todas las fuentes analizadas.

Varios proyectos se implementan con niños y niñas desde los 4 años de edad, pero la mayoría están destinadas a escolares entre 6 y 12 años. En las propuestas que se realizan en colaboración con universidades los destinatarios son dos poblaciones simultáneamente, los estudiantes de universidad y los escolares; los jóvenes son capacitados para trabajar con niños/as. Por su parte, los festivales invitan a asistir al público infantil y a sus acompañantes sin limitación de edad. Para la presentación de obras en competición se consideran "niños y jóvenes" a los realizadores/ as hasta los 18 años de edad.

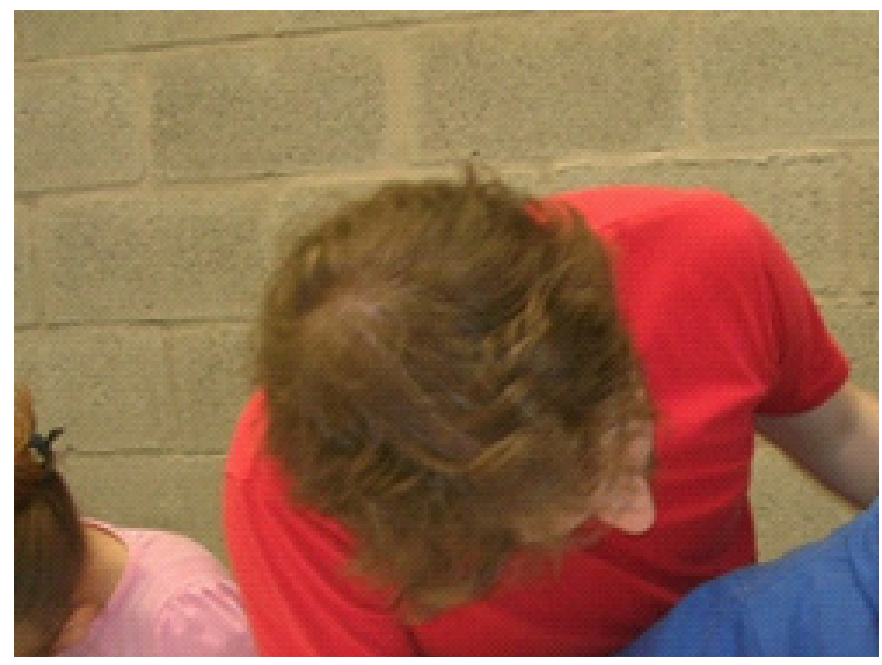

Figura 2. Un estudiante universitario de la Carrera de Audiovisión ayuda a un niño a diseñar un personaje. Proyecto Animate a animar. UNLa. Fuente: fotografía de la autora. 


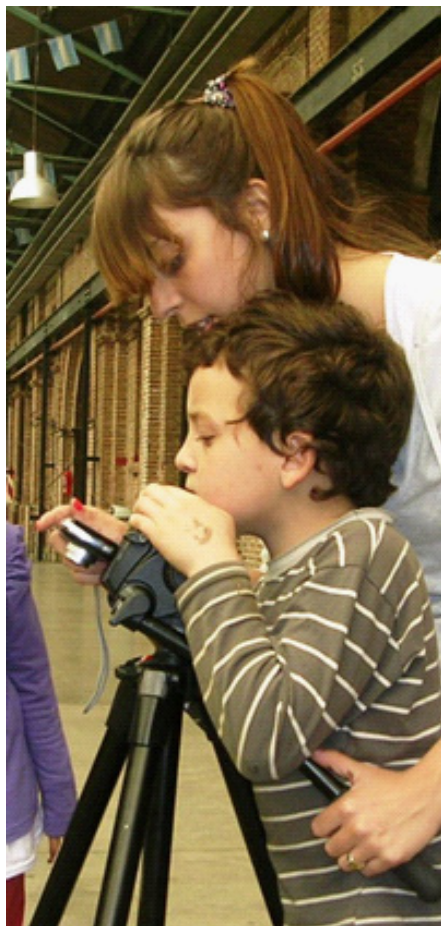

Figura 3. Un niño realiza una toma fotográfica con la guía de una estudiante. Proyecto Animate a animar. UNLa. Fuente: fotografía de la autora.

Los programas y proyectos comparten algunos propósitos generales tales como la formación de espectadores y la realización de piezas audiovisuales. Pero al analizar sus objetivos con detenimiento, es posible reconocer importantes diferencias que se vinculan con la perspectiva acerca de lo audiovisual que asume cada propuesta. Los objetivos se enuncian en estrecha relación con los contenidos y en este sentido se distinguen tres tipos: a) Abordan los medios de comunicación. Los niños/as "producen" con el propósito de analizar críticamente, defensivamente. El fin es la alfabetización medial/audiovisual. b) Abordan el cine desde una perspectiva cultural y artística. Los niños/as "crean" para encontrarse con la historia social, con la alteridad, con lo diverso. Crean para expresarse, para disfrutar, para conocer al otro y a sí mismos. c) Abordan el cine y la creación audiovisual como una vía "para". Los niños/as (en colaboración con jóvenes) realizan audiovisuales para incluir a grupos sociales desfavorecidos (vulnerados), para democratizar saberes, para ejercer un derecho, para cooperar entre comunidades/ instituciones/naciones.

Los proyectos muestran un amplio repertorio de estrategias didácticas, se observan prácticas comunes y además cada propuesta exhibe singularidades en consonancia con sus propósitos y sus concepciones acerca del cine y lo audiovisual. La modalidad didáctica del taller es postulada por todos los proyectos como la instancia de producción / creación audiovisual, esta forma de trabajo asume una configuración particular en cada caso según el contexto institucional, los propósitos, los contenidos. Así, es posible describir: a) Talleres ligados al encuadre de la institución escolar. b) Talleres centrados en el juego, la creatividad, la expresión y c) Talleres centrados en los componentes técnicos del trabajo audiovisual. Los talleres que se realizan en el marco de programas de cooperación generan dinámicas y secuencias didácticas muy específicas que deben ser estudiadas una a una en profundidad. 


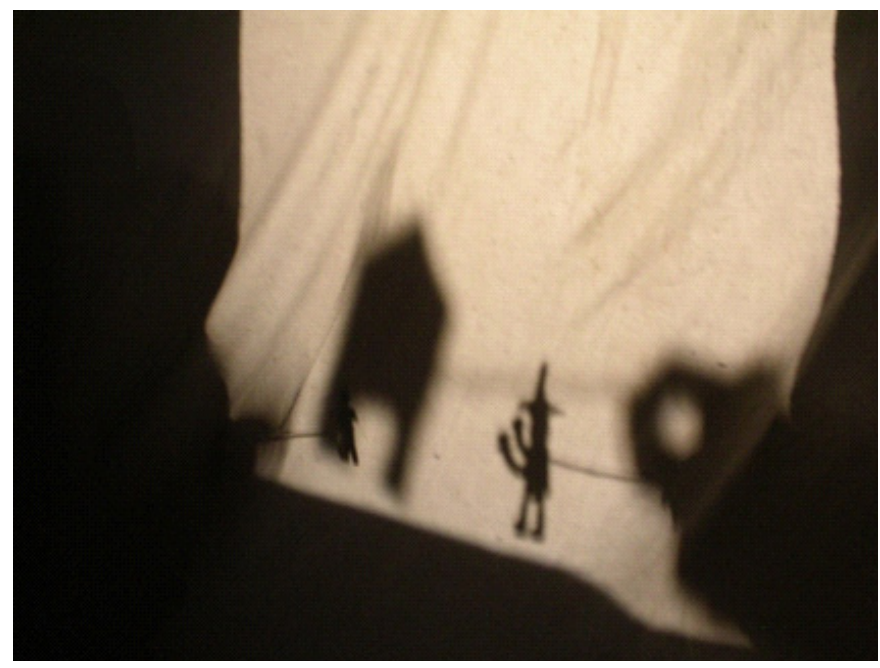

Figura 4. Teatro de sombras a partir de la obra de la realizadora Lotte Reiniger. Taller con grupo de 4 y 5 años. Cine + Chicos. Fuente: fotografía de la autora.

En todas las propuestas sus docentes a cargo cuentan con formación y/o se desempeñan como profesionales del campo audiovisual, además en algunos equipos también trabajan educadores, artistas de otras disciplinas, comunicadores sociales. En el caso de las universidades, se trata de estudiantes que cursan carreras ligadas al cine y el audiovisual quienes se encargan de conducir las actividades con la orientación y supervisión de sus profesores En varios proyectos se desarrollan actividades de formación del profesorado.

Todos los proyectos analizados desarrollan instancias de proyección de películas y material audiovisual, esta tarea se desarrolla con diferentes fines. Por una parte, cada proyecto selecciona "qué" exhibe a los aprendices, así se distinguen los proyectos que muestran: a) cine, b) programas de $\mathrm{TV}$, c) obras realizadas por otros niños y niñas. La exhibición de los trabajos realizados por niños/as a las familias, a la comunidad es una instancia presente en la mayoría los proyectos; en algunos casos se extiende a la participación en festivales. En algunas propuestas, las realizaciones de los menores son subidas a blogs, páginas o espacios virtuales de circulación y difusión audiovisual.

Todos estos proyectos, perspectivas, maneras de concebir y de hacer cine (diferentes entre sí a la luz del análisis discursivo y didáctico) se dan encuentro en los festivales de cine realizado para y por niños/as. La organización de los festivales cuenta con el apoyo de numerosos organismos públicos e instituciones privadas y públicas. Además de la exhibición, durante el festival se llevan a cabo otras actividades como talleres de creación para niños/as, encuentros con realizadores, en algunos se realizan actividades de formación para profesores. 


\section{Apuntes para una didáctica de la creación audiovisual infantil}

Del estudio de las prácticas surge que estas se anclan en corpus teóricos pertenecientes a campos disciplinares disímiles y con diferentes estatus epistemológicos. Así, se reconocen referencias, más o menos explicitas, a la historia y la teoría cinematográfica, la historia y la teoría del arte, la educación artística, la didáctica general y la pedagogía social.

Junto con las referencias teóricas, se observa la circulación y la puesta en práctica de conocimientos, destrezas y habilidades de carácter técnico y tecnológico implicados en la producción audiovisual. Además, en todos los casos se evidencian modos de hacer en los que subyacen concepciones pedagógicas, ideas acerca de la infancia, trabajo grupal, rol del profesor y uso de los materiales propios de la "sabiduría práctica docente" (Litwin, 2008), es decir, de aquellos conocimientos construidos en el desempeño del oficio de enseñar. En la misma dirección, se identifica en los discursos el "rumor teórico" (Cauquelin, 2012), ideas con un escaso nivel de estructuración teórica pero que, sin embargo, inciden fuertemente en las prácticas.

A continuación, se presentan algunas reflexiones, saberes y estrategias a modo de "faros", guías no prescriptivas sino orientadoras para las acciones educativas de creación audiovisual.

\section{Crear audiovisuales en las aulas}

Mirar películas o fragmentos de películas es desde hace décadas una práctica habitual en la escuela. Son numerosas las actividades, especialmente en el área de Ciencias Sociales, en las que el cine se emplea como una herramienta para la enseñanza. Por lo general, el cine es subsidiario, un medio para abordar contenidos curriculares y, para esto, se implementan diversas estrategias para su visionado y su posterior análisis

Pero el pasaje del análisis a la creación es una experiencia irremplazable, es una actividad vivencial, física, que involucra la cognición y la emoción, el registro sensible del entorno y de los demás, la imaginación. Todos los chicos y chicas deberían atravesar esta experiencia formativa y es aquí donde la escuela se impone, nuevamente, con uno de sus roles fundamentales: la democratización de prácticas y saberes socialmente valiosos.

¿Debería incluirse la creación audiovisual como un contenido escolar obligatorio? ¿A qué campo curricular pertenece esta tarea? El debate está en pleno desarrollo. Si bien hay cierto consenso en el valor formativo de la creación audiovisual, en la práctica, su implementación es dispar y se realiza con diferentes modalidades. En el Nivel Inicial y Primario, en algunos casos, la escuela se asocia o participa de programas especializados; en varias instituciones los maestros de Artes 
AUGUSTOWSKY / La creación audiovisual en la infancia. Estudio de experiencias en contextos educativos

Plásticas/Visuales asumen su desarrollo y, en muchas otras, los maestros de grado (generalistas) son los que realizan audiovisuales con sus alumnos y alumnas.

Cabe atender a las dificultades u obstáculos que se presentan al momento de realizar audiovisuales en las aulas, especialmente en la Primaria. Es verdad que la escuela no ha sido pensada en sus espacios ni en su organización cotidiana para realizar audiovisuales. Hacer audiovisuales implica cierto "desorden", una ruptura en los usos habituales de tiempos, espacios, materiales y en el desplazamiento de niños y niñas. Supone, además, un reacomodamiento de orden simbólico al incluir un modo de decir y hacer con escasa tradición escolar. Pero la limitación temporal puede ser convertida en un dispositivo creativo. Hay que volver a explorar el espacio, a revisitarlo con una mirada extrañada, de extranjero, para encontrar y elegir lugares, salas, pasillos o rincones que se adecúen a las condiciones de iluminación o de aislamiento acústico necesarios para la realización audiovisual y que, a su vez, permitan una sana convivencia con los alumnos de la escuela que realizan otras actividades. En términos simbólicos, las incorporaciones tecnológicas que se vienen dando en las escuelas van favoreciendo y legitimando el uso de "nuevos" lenguajes y medios de producción escolar.

Por lo general, la producción audiovisual en las aulas se asocia con un contenido disciplinar curricular; por ejemplo, la adaptación de un cuento, la representación de un hecho histórico, la comunicación de un conflicto medioambiental. Pero estas experiencias solo propician aprendizajes sólidos, significativos, cuando la tarea de creación audiovisual también se asume como un contenido de enseñanza; es decir, no basta con "chicos hagan en sus casas un audiovisual sobre este tema" (para reemplazar al clásico "hagan un poster"). Es importante recordar que el cine, el lenguaje audiovisual es un contenido de enseñanza autónomo con un inmenso valor por sí mismo, más allá de su sociedad virtuosa e indiscutible con las disciplinas escolares.

La creación audiovisual se enseña y el maestro de grado, solo o asociado con un realizador invitado, un especialista u otros colegas, es el encargado de planificar y conducir esta tarea. Así, la clase puede convertirse por unas jornadas en una pequeña comunidad creativa que explora, conoce, comunica e inventa con el medio audiovisual.

La dinámica colectiva de la creación audiovisual ofrece un territorio magnífico para abordar el trabajo grupal redistribuyendo los roles, desarmando estereotipos, asignando de manera no usual tareas y responsabilidades en el aula. Junto con las tareas grupales, es importante establecer momentos en los que cada alumno se vea confrontado individualmente con el riesgo, la emoción y el vértigo implicados en las acciones de creación. En la escuela, la producción audiovisual trabaja en sintonía con otras tareas destinadas a que los alumnos desarrollen su flexibilidad, se trata de un aprendizaje en el que los chicos someten a discusión sus ideas, debaten, 
argumentan, toman decisiones y actúan en consecuencia. Es un proceso creativo que se enriquece con la toma de consciencia y con la reflexión sobre todo lo realizado.

\section{La accesibilidad tecnológica. Educación audiovisual e inclusión social}

El escenario de diversificación y facilitación tecnológica para producir material audiovisual, sin duda alguna muy favorable, no garantiza per se su distribución equitativa para la infancia ni la inclusión de "nuevos" niños a este campo de conocimiento.

Resulta necesario establecer un ámbito formativo dedicado específicamente a la creación audiovisual infantil que no esté escindido de la educación artística en toda su complejidad (Huerta, 2003).

Al igual que en otras prácticas educativas, y especialmente en aquellas ligadas a las enseñanzas creativas, no es posible establecer relaciones causales, unívocas, simples o ingenuas entre la creación audiovisual y la inclusión social.

Los proyectos, que asumen el cine como parte de lo que Violeta Núñez (2007) denomina el tesoro de las herencias culturales, los niños y niñas hacen audiovisuales "en" la inclusión, que es condición necesaria para profundizar en un segundo nivel de inclusión. Esto implica acceder al universo simbólico de la creación en el que aprenden a expresarse, a conocer, a mirar el mundo mediante el lenguaje audiovisual.

Es fundamental continuar indagando y profundizando mediante estudios empíricos cómo incide la participación en este tipo de proyectos en la inclusión. La creación audiovisual, ¿modifica la percepción del mundo social por parte de los niños? La participación de chicos de sectores económicamente excluidos, ¿les permite visualizar lo audiovisual como un campo de futuro desarrollo laboral/profesional?

\section{La enseñanza audiovisual y el andamiaje adulto}

Al igual que en otros campos disciplinares, en la enseñanza audiovisual, los efectos de la no intervención docente son severos, deja a los chicos sin formación y sin andamiajes para el aprendizaje. Pero, además, en este caso, la no enseñanza propicia resultados (en caso de que lleguen a realizarlos) muy difíciles de ver o, "inmirables", lo que genera en los niños y las niñas frustración y desaliento.

En el otro extremo, docentes que toman todas las decisiones e intervienen unilateralmente (sin siquiera consultar a los niños) en cada etapa del proceso, especialmente en la edición, para corregir defectos o saltos narrativos. Finalmente, lo que se ve no es una creación audiovisual infantil. En el medio, hay un enorme abanico de posibilidades didácticas, creativas y buenas prácticas de enseñanza. 
Las creaciones audiovisuales de chicos requieren de un andamiaje adulto que no sea limitante o censor de sus ideas y sus necesidades expresivas. Cuando los niños proponen temas, en muchas ocasiones surgen estereotipos sociales o mediáticos. Los profesores toman, registran el interés de los niños y las niñas pero, partiendo de ese interés, cuestionan, muestran otras opciones, los invitan a probar nuevas formas expresivas, nuevos caminos, proponen transitar caminos metafóricos, poéticos. Las películas de diferentes creadores, épocas y países constituyen un universo inagotable de temas y de modos de abordarlos artísticamente que todo profesor debe explorar.

En la dinámica del largo proceso de creación audiovisual, es importante que los niños y niñas puedan ir adquiriendo herramientas técnicas, expresivas, comunicativas para poder manifestarse, para convertir en una creación audiovisual aquello que quieren contar, transmitir. La noción de "postura de autor" propone que los profesores ejerzan un rol de acompañamiento activo y escucha atenta a las ideas, a las elecciones estéticas y al discurso que desean construir los pequeños. El uso de los tiempos, de los espacios, de los materiales y de los dispositivos tecnológicos, así como la secuencia de tareas, debe ser planificado y anticipado muy meticulosamente (incluso en sus alternativas y flexibilidades), a fin de trazar parcelas confortables para la creación audiovisual.

\section{Los docentes para una enseñanza audiovisual creativa}

La educación audiovisual se despliega en una trama conformada por lo pedagógico, lo audiovisual y la expresión artística. Pero esto no atañe solamente a los niños: la propia producción artística y la experimentación enriquecen las formas de trabajo de los docentes y favorecen los abordajes creativos en la tarea con niños. La propia participación en actividades de creación (hacer audiovisuales, probar, buscar, desarmar y reconstruir, disfrutar, jugar con el movimiento y el sonido) es una tarea necesaria, fundamental para los educadores de todas las disciplinas involucrados en la educación audiovisual. Quien haya pasado por la experiencia de hacer un audiovisual resulta ser más paciente, tolerante y empático con los procesos creativos (no lineales) de los chicos.

Los "educadores audiovisuales" deben conjugar pericia técnica, habilidades de manejo grupal y conocimientos didácticos y artísticos. La complejidad de la enseñanza audiovisual requiere necesariamente del trabajo en equipo, es una práctica educativa que se potencia en la conjunción de recorridos formativos y profesionales de sus promotores. Un docente audiovisual debe contar entonces con una enorme disposición para trabajar genuinamente con otros.

\section{Caracterización de la creación audiovisual infantil}

Las obras audiovisuales realizadas por niños y niñas se comprenden y cobran sentido tanto en sus dimensiones estéticas como pedagógicas en contexto. Algunos 
de los rasgos que se observan con mayor frecuencia y que permiten trazar una caracterización de la creación audiovisual infantil son:

- La disposición de los niños a la tarea grupal, a la negociación, que se manifiesta en los guiones y en las imágenes. Si bien esta disposición es compartida con otras tareas, resulta fundamental para que la producción audiovisual pueda concretarse.

- El uso adecuado de la técnica de animación de arte plano (recortables) con los niños de entre 4 y 8 años.

- El aprovechamiento del "tiempo breve" del cortometraje.

- La presencia de todos los componentes y rasgos evolutivos de la producción plástico/visual.

- La creación de imágenes grupales híbridas, aditivas, con componentes heterogéneos (materiales, técnicas, texturas, escalas, morfología).

- Las bandas sonoras realizadas con las voces de los niños en los relatos y efectos que generan climas y texturas sonoras infantiles, tan distintivas y únicas como sus dibujos. Este rasgo es realmente singular y propio de la creación audiovisual infantil: ruiditos, gatos que cantan aullando, voces de monstruos, zombis, voces nasales y respiraciones proponen un clima de juego, de infancia, difícil de explicar con palabras. Es similar, quizás, a la banda de sonido de sus juegos, soliloquios, secretos que se murmuran al oído de un amigo.

- Las estructuras narrativas lineales, en muchos casos, sostenidas por canciones, cuentos, adaptaciones literarias. Este rasgo es en gran parte producto de la acción de los docentes; en general, se trata de un docente que escucha y "toma", pone en valor, acompaña las ideas de los chicos.

- El "estallido de lo verosímil", producto de las negociaciones intergrupales.

- Al igual que con los dibujos, las historias de los chicos son difíciles de incluir en un género cinematográfico en términos adultos; en muchos casos, transitan por varios géneros en pocos minutos.

- El uso frecuente del humor, la sátira y la ironía.

- El uso de títulos y créditos, habitualmente realizados con la caligrafía de los niños. Esta convención cinematográfica enseñada por los adultos, se recrea y asume sus propias cualidades estéticas en las creaciones infantiles. 


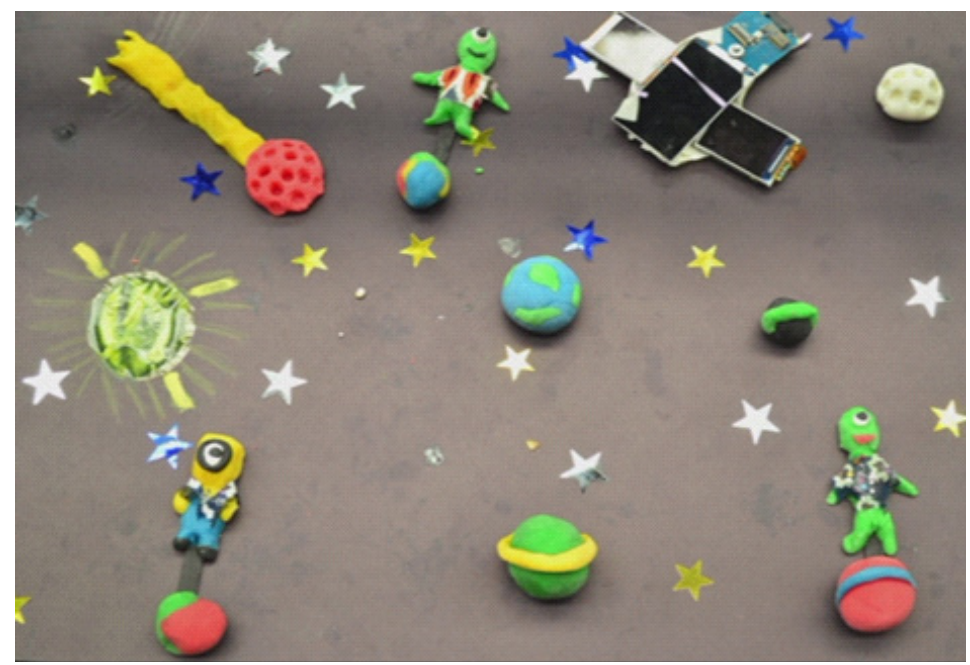

Figura 5. Fotograma del corto de animación "El fin del Universo". Animación de arte plano, personajes y elementos modelados en masa, lentejuelas y objetos construidos en cartón. Autoras: niñas de 8 años. Animate a animar. Fuente: gentileza archivo Animate a animar.

\section{La exhibición de creaciones y procesos}

En todos los proyectos hay instancias de mostrar, de hacer público, de hacer circular las obras realizadas; esta actividad asume características y un sentido propio en cada caso. Para los profesores, el nivel de exposición es muy alto y, por lo general, se plantea una tensión entre lo que el público conoce, acepta y está habituado a ver y las cualidades propias de las creaciones audiovisuales infantiles. Algunas estrategias, como exhibir-además de las obras-el detrás de escena, con los procesos y actividades realizadas, ayudan a poner en contexto y permiten dar a conocer cómo se enseña y cómo se hacen audiovisuales con niños, una práctica educativa que por lo general no se conoce demasiado.

Exhibir la creación audiovisual al público adulto implica no solo mostrar una obra o un espectáculo, sino también comunicar los estadios de un proceso creativo y los valiosos aprendizajes involucrados (Bergala, 2007).

Es importante reflexionar y determinar cuáles son los parámetros, qué se espera de los niños y, ante todo, no olvidar que las formas narrativas y las perspectivas de los chicos no son las de una producción profesional. La creación audiovisual, al igual que otros procesos de aprendizaje en la infancia, requieren de años de maduración $\mathrm{y}$, desde esta premisa, una evaluación debe tomar en cuenta también aspectos como la implicación personal de cada chico en el proceso, la coherencia del proceso y sus elecciones genuinas, grupales e individuales. no se trata de evaluar la producción de obras eficaces y de recepción transparente, sino de la verdadera comprensión y del respeto a los actos de creación infantil. 
La expansión de esta actividad requiere formar también a los espectadores y, así como hacía 100 años había que explicar que los monigotes que realizan los niños pequeños no son dibujos mal hechos, hoy podemos enseñar a mirar las obras audiovisuales de los niños y niñas, a aceptar sus vocecitas, su particular sentido del humor, a ser empáticos con sus historias, a reconocer y disfrutar de las ideas, las emociones y la poesía que habitan en la creación audiovisual infantil.

\section{Los festivales, espacio formativo y celebración colectiva}

Los niños y niñas que asisten a un festival de cine participan de una práctica social y cultural que se despliega en diferentes dimensiones. Intervienen y son parte de un ritual colectivo que es la visualización compartida de una película; una práctica que nació con el cine mismo y que fue mutando con las nuevas maneras de ver en la era digital. Se trata de una experiencia física, potente en términos sensoriales y afectivos, simbólicos y materiales.

Durante los festivales, los niños son espectadores, público privilegiado de un material que fue seleccionado para ellos pero, además, los pequeños son convocados a enviar sus creaciones. Así, gran parte de los chicos que asisten son también realizadores $y$, en muchos casos, comparten con sus pares creadores (chicos, jóvenes y adultos) estos eventos.

Los festivales configuran una experiencia de aprendizaje extraordinaria que se desenvuelve en el tiempo y el espacio de lo colectivo, en la proximidad con los otros que genera lo social. Son ante todo una fiesta que, con su forma particular de concebir el tiempo, los lugares y las relaciones con los demás, interrumpe el devenir de lo cotidiano y se convierte en un hecho excepcional. En estos se manifiesta una estrecha colaboración entre la experiencia artística, el juego y la celebración colectiva (Gadamer, 1996).

En términos didácticos su objetivo es la formación de un espectador activo, consciente y creativo, que continúa abordando lo mirado más allá del tiempo específico de su proyección. El festival puede ser un lugar para la "participación estética" (Sorlin, 2010), es decir un modo de ver que se expande en múltiples prácticas creativas. El niño/a espectador/a sabe que debe prolongar el contacto, retomar la obra y modificarla, someterla a sus preguntas, transformarla en un material sobre el cual ejercerá su capacidad inventiva. No se trata de simple consumo. La participación estética se despliega en actividad creadora y demanda, como la creación en la que se inspira, medios de expresión. Se trata de asumir plenamente una doble condición: observadores que crean / creadores que observan. 
AUGUSTOWSKY / La creación audiovisual en la infancia. Estudio de experiencias en contextos educativos

\section{Referencias}

Augustowsky, G. (2015). La creación audiovisual infantil como práctica educativa. Estudio de experiencias y discursos en contexto (tesis doctoral bajo la dirección de Marián López Fdez. Cao). Universidad Complutense de Madrid, España. Disponible en https://eprints.ucm.es/38971/

Augustowsky, G. (2017). La creación audiovisual en la infancia. De espectadores a productores. Buenos Aires: Paidós.

Baigorri, L. (2004). Vídeo: primera etapa. El vídeo en el contexto social y artístico de los años 60 y 70. Madrid: Ed. Brumaria

Barbosa, A. M. (2011). La investigación en arteeducación en Brasil. En I. Agirre, L. Jiménez, L. Pimentel (coord.) (2011) Educación artística, cultura y ciudadanía. De la teoría a la práctica (pp. 123-128). Madrid: OEI.

Bergala, A. (2007). La hipótesis del cine. Pequeño tratado sobre la transmisión del cine en la escuela y fuera de ella. Barcelona: Leartes Educación.

Buckingham, D. (2008). Más allá de la tecnología. Aprendizaje infantil en la era de la cultura digital. Buenos Aires: Manantial.

Cauquelin, A. (2012). Las teorías del arte. Buenos Aires: Adriana Hidalgo Editora.

Ferrés i Prats, J. (2014). Las pantallas y el cerebro emocional. Barcelona: Gedisa.

Gadamer, H. (1996). La actualidad de lo bello. Barcelona: Paidós Ibérica.

Huerta, R. (2003). Almas gemelas: artes y medios. EARI Educación Artística Revista de Investigación, 1, 233-246.

Kress, G. (2003). Literacy in the new media age. Routledge.

Litwin, E. (2008). El oficio de enseñar. Buenos Aires. Paidós.

Mampaso Martínez, A. (2006). Para todos tiene la muerte una mirada. Arteterapia: papeles de arteterapia y educación artística para la inclusión social, 1, 161-178.

Morduchowicz, R. (2003). El sentido de una educación en medios. Revista Iberoamericana de Educación. OEI, 32, 35-47.

Núñez, V. (2007). Pedagogía Social: un lugar para la educación frente a la asignación social de los destinos. Conferencia MEC y T. Argentina.

Sorlin, P. (2010). Estéticas del audiovisual. Buenos Aires: La marca editora. 